\title{
La glycémie et la faim, la diurèse et la soif sous le joug du GLP-1: fiction ou réalité?
}

Il n'est pas de semaine sans qu'on voit publiés les effets de l'invalidation d'un gène chez la souris. Mais il reste surprenant de constater que les phénotypes obtenus ne correspondent pas toujours aux phénotypes attendus, mettant en doute le rôle in vivo de la protéine étudiée [1]. Ajouté au cas d'autres protéines et peptides régulateurs, l'exemple du GLP-1 ( $g l u$ cagon-like peptide 1) vient confirmer cette observation. Avant tout considéré comme un facteur incrétine* puissant, le GLP-1 sécrété par l'intestin à la suite d'un repas, et stimulateur de la sécrétion d'insuline, est un membre actif du contrôle de l'homéostasie glucidique in vivo [2]. Récemment identifié au niveau du système nerveux central et doublement pressenti comme facteur de satiété $(\mathrm{m} / \mathrm{s}$ $n^{\circ} 3$, vol. 12, p. 392) [3, 4], ce peptide vient d'être investi de nouvelles fonctions aussi vitales que l'inhibition de la soif, l'activation de la diurèse et de la natriurèse [4]. Le récepteur GLP$1 \mathrm{R}$ de ce peptide de la famille des protéines à sept domaines transmembranaires couplés à des protéines $\mathrm{G}$ [5] est localisé, en particulier, dans le noyau paraventriculaire hypothalamique (structure impliquée dans la satiété) et dans des zones cérébrales sensibles à l'osmolarité plasmatique, ce qui a orienté les auteurs vers la recherche d'un effet du GLP-1 sur la satiété et l'homéostasie des fluides [3]. De fait, l'injection de GLP-1 dans

* Effet incrétine: différence de réponse insuline obtenue après une charge glucidique orale et par voie intravei- le noyau paraventriculaire a non seulement un effet anorexigène sur les animaux, mais diminue aussi la soif. L'extendine (9-39), un antagoniste spécifique du GLP-1, n'a aucune action seule, mais abolit l'action inhibitrice du GLP-1 sur la faim et la soif. L'effet sur la soif est retrouvé après injection intrapéritonéale et peut même être observé chez des animaux préalablement privés de boisson, ou bien dont la sensation de soif a été stimulée par l'angiotensine II [3]. L'injection intracérébroventriculaire de GLP-1 augmente aussi la diurèse et la natriurèse, indépendamment de toute modification préalable de l'osmolarité plasmatique ou de la glycémie. L'arginine vasopressine plasmatique augmente secondairement après injection de GLP-1, probablement en réponse à la natriurèse. Enfin, aucun effet d'aversion du goût ni aucune modification de l'activité locomotrice exploratrice des rats traités n'ont pu être associés à l'action du GLP-1. Les mécanismes de suppression de la soif par le GLP-1 administré par voies cérébrale et intrapéritonéale suggèrent donc que sont impliqués des récepteurs GLP-1 présents dans différentes régions centrales dont certaines sont dépourvues de barrière hémato-encéphalique, une situation déjà décrite pour l'angiotensine II et qui pourrait expliquer l'action du GLP-1 intestinal sur les centres nerveux de la soif. En revanche, l'effet diurétique du GLP-1 ne semble dépendre que de la production centrale de GLP-1.

Toutes ces données laissaient présager que l'inactivation du gène $G L P$ -
$1 R$ par recombinaison homologue aurait d'importantes conséquences. Cependant, il n'en est rien, ce qui illustre une nouvelle fois les limites de ce type d'expérience reposant sur l'administration de peptides exogènes in vivo. En fait, le comportement alimentaire des souris $G L P-1 R^{-1}$ n'est pas significativement perturbé [4]. En revanche, le contrôle de la glycémie est affecté. Ainsi, le pic d'augmentation de la glycémie observé chez toutes les souris trente minutes après l'administration orale de glucose, reste élevé uniquement chez les souris mutantes, particulièrement chez les mâles. Bien que moins sévère, le signe d'une intolérance au glucose se manifeste également chez les souris $G L P-1 R^{-1}$ ayant reçu le glucose par voie intrapéritonéale. En outre, en accord avec l'action insulinotrope confirmée du GLP-1, l'absence des récepteurs de ce peptide chez les souris $G L P-1 R^{-/-}$se manifeste par une très faible augmentation de l'insulinémie, précocement après ingestion de glucose (30 minutes), alors que cette valeur est normale à jeun ou une heure après ingestion de glucose. De façon plus inattendue, la sécrétion de glucagon, physiologiquement inhibée par le GLP-1 après un repas, ne semble pas altérée chez les souris mutantes dont la glucagonémie est normale. Quel que soit le site d'entrée du glucose dans la circulation, le GLP-1 et son récepteur constituent donc à l'évidence un axe important pour la réponse insulinique et, par conséquent, participent activement au contrôle de la glycémie. Contrairement à toute attente, 
le rôle du GLP-1 sur le comportement alimentaire reste encore aujourd'hui énigmatique. En effet, chez les souris dépourvues de récepteurs du peptide, le poids corporel (des mâles et femelles de 4 à 24 semaines), comme l'appétit après un jeûne de 20 heures, sont tout à fait comparables à ceux des souris témoins. En revanche, le GLP-1 (en injection centrale) n'inhibe plus la prise alimentaire chez les souris GLP$1 R^{-/}$. Ces résultats démontrent que le GLP-1 dont on sait qu'il n'est pas le seul facteur de satiété identifié, n'a en tout cas pas de rôle déterminant in vivo sur le comportement alimentaire, ni même sur le contrôle de la masse corporelle. En revanche, comme attendu, le GLP-1 est à part entière un facteur important du contrôle de la glycémie, probablement en agissant sur la sécrétion d'insuline, mais aussi sur la disponibilité en glucose des tissus, comme cela avait déjà été suggéré [6]. Devant ces résultats, on peut penser que le GLP-1 pourrait donc trouver sa place dans le traitement des diabètes, et même du diabète insulinoprive, si son effet sur la consommation tissulaire du glucose était confirmé.
1. Lévy-Strauss M. Les effets inattendus des expériences de recombinaison homologue. Med Sci $1994 ; 10: 565-7$.

2. Göke R, Fehman HC, Göke B. Glucagon-like peptide-1(7-36) amide is a new incretin/enterogastrone candidate. Eur J Clin Invest 1991; 21 : 135-44.

3. Turton MD, et al. (15 auteurs). A role for glucagon-like peptide 1 in the central regulation of feeding. Nature 1996; 379: 69-72.

4. Tang-Christensen M, Larsen PJ, Rüdiger Gôke, Fink-Jensen A, Jessop DS, Moller M, Sheikh SP. Central administration of GLP-1-(7-36) amide inhibits food and water intake un rats. Am J Physiol 1996; 271 : R848-56.

5. Scrocchi LA, Brown TJ, MacLusky N, Brubaker PL, Auerbach AB, Joyner AL, Drucker DJ. Glucose intolerance but normal satiety in mice with a null mutation in the glucagon-like peptide 1 receptor gene. Nature Med 1996; 2: 1254-8.

6. Villanueva-Penacarrillo ML, Alcantara AI, Clemente F, Delgado E, Valverde I. Potent glycoge-

B.A. nic effect of GLP-1(7-36) amide in rat skeletal muscle. Diabetologia 1994; 37 : 1163-6. 